\title{
Clinical management of sepsis
}

\author{
SM Lam *, Arthur CW Lau, Rex PK Lam, WW Yan
}

\section{A B S T R A C T}

Sepsis is a common cause of hospital admission worldwide and contributes significantly to morbidity and mortality. The definition of sepsis has evolved from the 1991 American College of Chest Physicians/ Society of Critical Care Medicine definition based on the criteria of systemic inflammatory response syndrome, to the 2016 Sepsis-3 definition that incorporates the Sequential Organ Failure Assessment score. The landmark trial on protocolised early goal-directed therapy was published in 2001, but three subsequent multicentre randomised controlled trials (ProCESS, ARISE, and ProMISe) in 2014-2015 did not confirm a survival benefit with protocolised care. Over the years, there has been considerable improvement in sepsis outcome and management that hinges on early detection; timely source control; prompt, appropriate, and correctly dosed antibiotics; aggressive fluid resuscitation; and shock reversal. These are all directed by repeated bedside assessment. This article summarises recent developments and landmark trials that should guide current sepsis management.

\begin{tabular}{l} 
Hong Kong Med J 2017;23:296-305 \\
\hline DOI: 10.12809/hkmj165057 \\
${ }^{1}$ SM Lam *, MB, BS, FHKAM (Medicine) \\
${ }^{1}$ ACW Lau, MB, BS, FHKAM (Medicine) \\
${ }^{2}$ RPK Lam, MB, BS, FHKAM (Emergency Medicine) \\
${ }^{1}$ WW Yan, MB, BS, FHKAM (Medicine) \\
${ }^{1}$ Department of Intensive Care, Pamela Youde Nethersole Eastern \\
Hospital, Chai Wan, Hong Kong \\
${ }^{2}$ Emergency Medicine Unit, Li Ka Shing Faculty of Medicine, The \\
University of Hong Kong, Pokfulam, Hong Kong \\
* Corresponding author: lamsm2@ha.org.hk
\end{tabular}

\section{Introduction}

Sepsis is a common cause of hospital admission worldwide. The annual incidence of sepsis has been reported to be approximately 300 to 1031 per 100000 population in the US, and is increasing. ${ }^{1}$ Inhospital mortality, however, decreased from $35 \%$ in 2000 to $<20 \%$ in $2013 .{ }^{2}$ Numerous studies have been performed or are ongoing in this field. The following discussion provides an update on the change to sepsis definition, three recent trials on protocolised early goal-directed therapy (EGDT), and individual components of sepsis management.

\section{Defining and recognising sepsis: from systemic inflammatory response syndrome to Sequential Organ Failure Assessment score and the role of biomarkers}

In 1991, sepsis was defined as fulfilling two or more than two systemic inflammatory response syndrome (SIRS) criteria in the presence of infection (Table 1). ${ }^{3}$ Many seriously infected patients (eg old or immunocompromised), however, are unable to mount a SIRS. Using SIRS criteria to define severe sepsis will miss one in eight otherwise similar patients with substantial mortality. ${ }^{2}$ In addition, the mortality risk has been shown to increase linearly with each additional SIRS criterion and there is no transition point noted at a threshold of two SIRS criteria.
To acknowledge the above shortcomings, the Sepsis-3 (Third International Consensus Definitions for Sepsis and Septic Shock) in 2016 redefined sepsis as "life-threatening organ dysfunction caused by a dysregulated host response to infection". ${ }^{4}$ Organ dysfunction is identified as "an acute change in the total Sequential Organ Failure Assessment (SOFA) score of $\geq 2$ points" (Table 1). In addition, a quick SOFA (qSOFA) score was introduced for bedside screening. Meeting two or more than two qSOFA criteria (respiratory rate $\geq 22 / \mathrm{min}$, altered mentation with a Glasgow Coma Scale score of $<15$, systolic blood pressure $\leq 100 \mathrm{~mm} \mathrm{Hg}$ ) should prompt consideration of possible infection in undiagnosed patients, investigation for organ dysfunction that defines sepsis in infected patients, and initiation of sepsis management where appropriate. ${ }^{4}$ Despite these recent changes in definition, clinicians should maintain a high index of suspicion and always consider sepsis as a possible explanation/diagnosis when faced with new-onset organ dysfunction in a patient.

Apart from clinical assessment, various serum biomarkers have been studied for their potential role in early diagnosis of sepsis. C-reactive protein is commonly used but it has a low specificity for sepsis. Procalcitonin (PCT) is a prohormone of calcitonin that is released into the circulation in response to severe systemic inflammation due to bacterial infection. A recent meta-analysis showed its clinical value in diagnosing sepsis in critically ill patients (an area under the receiver operating characteristic 
curve of 0.85$).^{5}$ The meta-analysis, however, was limited by substantial heterogeneity across different studies, a wide range of cut-offs used, absence of a true reference diagnostic standard, and potential publication bias. It is noteworthy that PCT can be falsely elevated in inflammation due to other causes, such as trauma, rhabdomyolysis, surgery, severe pancreatitis, autoimmune disorders, cardiogenic shock, and following prolonged resuscitation. It cannot be solely relied on to discriminate sepsis from other causes of inflammation, but a plasma PCT level of $\geq 0.5 \mathrm{ng} / \mathrm{mL}$ is a helpful adjunct when interpreted along with additional clinical information and serial monitoring might have a role in guiding subsequent antibiotic treatment (see below). In case of doubt, it is advisable to initiate treatment for sepsis early, and adjust subsequent management and antibiotics according to the patient's clinical progress, results of investigations, and possibly serial PCT monitoring.

\section{Update on protocolised management: from early goal- directed therapy to ProCESS- ARISE-ProMISe}

In 2001, Rivers et $\mathrm{al}^{6}$ randomised 263 patients with severe sepsis or septic shock in an emergency department (ED) to EGDT or usual care. The sequential goals of EGDT were central venous pressure (CVP) achieved by fluid resuscitation, mean arterial pressure (MAP) with vasopressors,

\section{膿毒症的臨床治理 \\ 林倩雯、劉俊穎、林沛堅、殷榮華}

膿毒症 (敗血症) 是很多國家一個最常見的入院原因, 其發病率和死 亡率很高。膿毒症的定義隨着這數十年的演變而有所修正。1991年美 國胸科醫師學院與重症監護醫學學會共同商討, 按全身炎症反應綜合 症對膿毒症作定義。直至2016年第三次國際膿毒症共識會上, 把器官 衰竭評估分數納入定義中。2001年發表了一項有關早期目標導向的 流程化治療, 這項研究極具里程碑意義。可惜2014及2015年進行的 三項多中心隨機對照研究, 包括發起於美國的早期膿毒性休克流程化 治療試驗（ProCESS）、發起於澳大利亞和紐西蘭的澳大拉西亞膿毒 症復更生評估試驗（ARISE）, 以及發起於英國的膿毒症流程化管理試 驗（ProMISe）, 均未確認流程化治療能提高病人生存效益。這些年 來, 膿毒症的治療結果有相當大程度的改善, 這取決於早期發現、及 時的病源控制、及時處方適當和正確劑量的抗生素、給予充分性液體 復更生治療, 以及休克逆轉。以上各項均透過不斷重複的床邊評估指導 而成。本文總結有關治理膿毒症的最新發展, 以及歸納對現行治療方 法相關的具指標性臨床試驗研究。

TABLE I. Old and new definitions of sepsis ${ }^{3}$

\begin{tabular}{|c|c|c|}
\hline & Definitions & Comments \\
\hline \multicolumn{3}{|l|}{ Sepsis-1, 1991} \\
\hline Sepsis & SIRS ${ }^{\star}$ with infection (presumed or proven) & $\begin{array}{l}\text { SIRS can be non-infectious in aetiology. Only infection plus SIRS } \\
\text { is termed sepsis. Not all patients with serious infection necessarily } \\
\text { show SIRS features despite having organ dysfunction }\end{array}$ \\
\hline Severe sepsis & $\begin{array}{l}\text { Sepsis (as above) with evidence of acute organ } \\
\text { dysfunction }\end{array}$ & $\begin{array}{l}\text { Gives a false impression that infection must go through the three } \\
\text { stages of sepsis, severe sepsis, and septic shock; or that organ } \\
\text { dysfunction must have SIRS }\end{array}$ \\
\hline Septic shock & $\begin{array}{l}\text { Sepsis with persistent hypotension after fluid } \\
\text { resuscitation }\end{array}$ & $\begin{array}{l}\text { Emphasis placed on circulation (blood pressure) alone without } \\
\text { considering the metabolic (lactate) component }\end{array}$ \\
\hline Sepsis-2, 2001 & Unchanged & The list of signs and symptoms associated with sepsis was expanded \\
\hline \multicolumn{3}{|l|}{ Sepsis-3, 2016} \\
\hline Sepsis & $\begin{array}{l}\text { Life-threatening organ dysfunction } † \text { caused by a } \\
\text { dysregulated host response to infection }\end{array}$ & $\begin{array}{l}\text { To recognise the finding that infections can result in local organ } \\
\text { dysfunction (reflected by the SOFA score) without triggering a } \\
\text { dysregulated host response (the old SIRS criteria) }\end{array}$ \\
\hline Septic shock & $\begin{array}{l}\text { A subset of sepsis with persistent hypotension } \\
\text { requiring vasopressors to maintain MAP of } \\
\geq 65 \mathrm{~mm} \mathrm{Hg} \text { and a serum lactate level of }>2 \mathrm{mmol} / \mathrm{L} \\
\text { despite adequate volume resuscitation }\end{array}$ & $\begin{array}{l}\text { The term 'severe sepsis' is deleted, and both circulatory and } \\
\text { metabolic abnormalities are considered. Whether the new Sepsis-3 } \\
\text { criteria improves clinical outcomes remains to be validated }\end{array}$ \\
\hline
\end{tabular}

Abbreviations: MAP = mean arterial pressure; SIRS = systemic inflammatory response syndrome; SOFA = Sequential Organ Failure Assessment

* $\geq$ Two of the following: (a) temperature $>38^{\circ} \mathrm{C}$ or $<36^{\circ} \mathrm{C}$, (b) heart rate $>90 / \mathrm{min}$, (3) respiratory rate $>20 / \mathrm{min} \mathrm{or} \mathrm{PaCO}_{2}<32 \mathrm{~mm} \mathrm{Hg}(4.3 \mathrm{kPa}$ ), (4) white blood cell count $>12000 / \mathrm{mm}^{3}$ or $<4000 / \mathrm{mm}^{3}$ or $>10 \%$ immature bands

+ Defined by an acute change of $\geq 2$ points in the SOFA score; 6 components including: respiratory (partial pressure of oxygen in arterial blood/fractional inspired oxygen $\left[\mathrm{PaO}_{2} / \mathrm{FlO}_{2}\right]$ ratio), neurological (Glasgow Coma Scale score), cardiovascular (MAP and vasopressor use), renal (serum creatinine and urine output), hepatic (bilirubin level), and platelet count 
haemodynamic goals, use of CVP and $\mathrm{ScvO}_{2}$ monitoring, blood transfusion, dobutamine, and resultant higher costs of its implementation. Subsequently, three large-scale multicentre randomised controlled trials were published in 2014-2015: the ProCESS (Protocolized Care for Early Septic Shock) trial, ${ }^{8}$ the ARISE (Australasian Resuscitation in Sepsis Evaluation) trial, ${ }^{9}$ and the ProMISe (Protocolised Management in Sepsis) trial..$^{10}$ All three studies were negative; there was no survival benefit using protocolised care compared with usual care (Table 2). ${ }^{6.8-10}$

A lack of survival benefit of EGDT in the latest three trials may be the result of improved sepsis management since the original trial: nearly all patients received antibiotics within 6 hours of presentation, and a significant amount of fluid was already administered before randomisation (Table 2). Treatment in the usual care groups was guided by clinical assessment of volume and perfusion status, and achieved similar mean and systolic blood pressures at the end of the intervention period. These trials demonstrated that CVP and $\mathrm{ScvO}_{2}$ goals confer no additional benefit for sepsis survival.

In response to the new evidence, the SSC Guidelines updated its 6-hour bundle in April 2015, and recommended reassessment in the event of persistent arterial hypotension with either physical examination or "two of the following (measure CVP, measure $\mathrm{ScvO}_{2}$, bedside cardiovascular ultrasound, dynamic assessment of fluid responsiveness with passive leg raise or fluid challenge)" ${ }^{11}$

TABLE 2. Comparison of the original EGDT trial, with the ProCESS, ARISE and ProMISe trials. (a) Study characteristics and (b) interventions and outcomes ${ }^{6,8-10}$

(a) Study characteristics

\begin{tabular}{|c|c|c|c|c|}
\hline & Rivers et al, $2001^{6}$ & ProCESS, $2014^{8}$ & ARISE, $2014^{9}$ & ProMISe, $2015^{10}$ \\
\hline Country (No. of centres) & United States (1) & United States (31) & $\begin{array}{l}\text { Australia, New Zealand, } \\
\text { Hong Kong, Finland, } \\
\text { Republic of Ireland (51) }\end{array}$ & England (56) \\
\hline Enrolment period & Mar 1997 to Mar 2000 & Mar 2008 to May 2013 & Oct 2008 to Apr 2014 & Feb 2011 to Jul 2014 \\
\hline No. of patients & 263 & 1341 & 1600 & 1260 \\
\hline Usual care & 133 & 456 & 804 & 630 \\
\hline EGDT & 130 & 439 & 796 & 630 \\
\hline Protocol-based standard therapy & N/A & 446 & $\mathrm{~N} / \mathrm{A}$ & $\mathrm{N} / \mathrm{A}$ \\
\hline $\begin{array}{l}\text { No. of patients (\% screened) eligible but } \\
\text { not randomised due to study logistic } \\
\text { issues or exclusion by clinicians }\end{array}$ & 0 & $1191(9.4)$ & $797(22.4)$ & $1444(23.3)$ \\
\hline
\end{tabular}

(b) Interventions and outcomes

\begin{tabular}{|c|c|c|c|c|c|c|c|c|c|}
\hline & \multicolumn{2}{|c|}{ Rivers et al, $2001^{6}$} & \multicolumn{3}{|c|}{ ProCESS, $2014^{8}$} & \multicolumn{2}{|c|}{ ARISE, $2014^{9}$} & \multicolumn{2}{|c|}{ ProMISe, $2015^{10}$} \\
\hline & EGDT & $\begin{array}{l}\text { Usual } \\
\text { care }\end{array}$ & EGDT & $\begin{array}{l}\text { Protocol-based } \\
\text { standard } \\
\text { therapy }\end{array}$ & $\begin{array}{l}\text { Usual } \\
\text { care }\end{array}$ & EGDT & $\begin{array}{l}\text { Usual } \\
\text { care }\end{array}$ & EGDT & $\begin{array}{l}\text { Usual } \\
\text { care }\end{array}$ \\
\hline Baseline APACHE II score & $20.4 \pm 7.4$ & $21.4 \pm 6.9$ & $20.8 \pm 8.1$ & $20.6 \pm 7.4$ & $20.7 \pm 7.5$ & $15.4 \pm 6.5$ & $15.8 \pm 6.5$ & $18.7 \pm 7.1$ & $18.0 \pm 7.1$ \\
\hline Baseline lactate level (mmol/L) & $7.7 \pm 4.7$ & $6.9 \pm 4.5$ & $4.8 \pm 3.1$ & $5.0 \pm 3.6$ & $4.9 \pm 3.1$ & $6.7 \pm 3.3$ & $6.6 \pm 2.8$ & $7.0 \pm 3.5$ & $6.8 \pm 3.2$ \\
\hline \multicolumn{10}{|l|}{ Total intravenous fluid (mL) } \\
\hline Before randomisation & $\mathrm{N} / \mathrm{A}$ & $\mathrm{N} / \mathrm{A}$ & 2254 & 2226 & 2083 & 2515 & 2591 & 2100 & 2290 \\
\hline 0-6 Hours & 4981 & 3499 & 2805 & 3285 & 2279 & 1964 & 1713 & 2000 & 1784 \\
\hline Antibiotics within 6 hours (\%) & 86.3 & 92.4 & 97.5 & 97.1 & 96.9 & 100 & 100 & 100 & 100 \\
\hline Vasopressor (\%) & 27.4 & 30.3 & 54.9 & 52.2 & 44.1 & 66.6 & 57.8 & 53.3 & 46.6 \\
\hline Dobutamine (\%) & 13.7 & 0.8 & 8.0 & 1.1 & 0.9 & 15.4 & 2.6 & 18.1 & 3.8 \\
\hline Red cell transfusion (\%) & 64.1 & 18.5 & 14.4 & 8.3 & 7.5 & 13.6 & 7.0 & 8.8 & 3.8 \\
\hline Mechanical ventilation (\%) & 53.0 & 53.8 & 26.4 & 24.7 & 21.7 & 22.2 & 22.4 & 20.2 & 19.0 \\
\hline \multicolumn{10}{|l|}{ Mortality } \\
\hline In-hospital (\%) & 30.5 & 46.5 & $\mathrm{~N} / \mathrm{A}$ & $\mathrm{N} / \mathrm{A}$ & $\mathrm{N} / \mathrm{A}$ & 14.5 & 15.7 & 25.6 & 24.6 \\
\hline 60-Day (\%) & 44.3 & 56.9 & 21.0 & 18.2 & 18.9 & $\mathrm{~N} / \mathrm{A}$ & $\mathrm{N} / \mathrm{A}$ & $\mathrm{N} / \mathrm{A}$ & $\mathrm{N} / \mathrm{A}$ \\
\hline 90-Day (\%) & $\mathrm{N} / \mathrm{A}$ & N/A & 31.9 & 30.8 & 33.7 & 18.6 & 18.8 & 29.5 & 29.2 \\
\hline
\end{tabular}

Abbreviations: APACHE = acute physiology and chronic health evaluation; EGDT = early goal-directed therapy; N/A = not available/applicable 


\section{Clinical management: initial resuscitation and treatment}

\section{Source control}

Source control includes drainage of any infected fluid collection, debridement of infected solid tissue, and removal of infected foreign bodies or devices. It should best be achieved within 12 hours of identification by imaging and/or diagnostic sampling of the infection foci. Minimally invasive intervention including percutaneous and endoscopic treatments should be considered, but surgery is indicated if control remains inadequate or if there is diagnostic uncertainty. Damage-control surgery for lifethreatening peritonitis is associated with improved outcomes. ${ }^{12}$ It involves an abbreviated initial laparotomy for haemorrhage and contamination control, followed by resuscitation before the final definitive repair and abdominal closure.

\section{Antibiotics}

Delay in antimicrobial treatment is associated with increased mortality, adverse clinical outcome, and longer intensive care unit (ICU) and hospital stay. ${ }^{13}$ Effective intravenous antimicrobials should be initiated as soon as possible after recognition and within 1 hour for both sepsis and septic shock. ${ }^{14}$ One study showed that each hour delay reduces survival by $7.6 \%$ in the first 6 hours following the onset of septic shock..$^{15}$ Although a recent metaanalysis pooling data from 11 observational studies showed no survival benefit of early antibiotic therapy ${ }^{16}$ it failed to analyse all eligible studies and lacked microbiological considerations. Early therapy remains logical, especially in patients with severe infections, although the optimum time frame for administration remains unknown. ${ }^{17}$ Delay in administration can occur anywhere, from ED triage, making a diagnosis, antibiotic order, drug dispensary to the actual administration, and should be addressed with clinical, administrative, and logistics measures to improve timeliness of treatment.

The choice of initial empirical antimicrobials should be broad enough to cover the likely pathogens, while also taking into account recent culture results, host factors, and susceptibility patterns. The EPIC II (Extended Prevalence of Infection in Intensive Care) study showed that in Asia, the common infective sources are the respiratory system, abdomen, blood stream, and renal/urinary tract, while the commonest organisms are Streptococcus pneumoniae, vancomycin-sensitive Enterococcus, Klebsiella spp, Pseudomonas spp, and Acinetobacter spp. ${ }^{18}$ Local microbiologists can regularly provide antibiotic sensitivity patterns for reference.

Combination therapy, defined as administration of two or more different classes of antimicrobials with different mechanisms of action, has the advantages of broadening the spectrum of coverage, and possible additive or synergistic effects on pathogens. Metaanalyses showed that combination antibiotic therapy improves survival in the most severely ill patients with septic shock, but may be detrimental to lowrisk patients and increases nephrotoxicity. ${ }^{19,20}$ Once the causative pathogens and their susceptibility patterns are known, de-escalation of antimicrobial therapy should follow to prevent development of resistance, as well as reduce drug toxicity and cost. Discontinuing antibiotics can be considered when PCT is $\leq 0.5 \mathrm{ng} / \mathrm{mL}$ or serial monitoring shows a decline of $\geq 80 \%$ of its peak value. ${ }^{21}$

Appropriate antibiotic dosing to achieve effective bacterial killing while preventing toxicity and emergence of resistance is also important. This is particularly relevant in critically ill patients with substantial pharmacokinetic variability (Table 3), who are infected by pathogens with higher minimum inhibitory concentrations (MIC). Individualised dosing adjustment requires knowledge of pharmacokinetic targets and MIC for the organism. Readers can refer to published reviews for specific recommendations..$^{22,23}$ In general, changes to the volume of distribution will affect initial dosing, while changes in drug clearance will affect the maintenance dose. Killing by time-dependent antibiotics (eg $\beta$ lactams) correlates with the time fraction when serum drug concentration exceeds MIC. This can be achieved by frequent dosing and use of continuous infusion. Conversely, concentration-dependent killing (eg aminoglycosides) correlates with the ratio of peak drug concentration to MIC. A higher dosage with extended dosing intervals will maximise killing while minimising toxicity. Due to the complexity and variability of various factors at play, therapeutic drug monitoring has been advocated in the critically ill patients but remains to be available universally. ${ }^{22-24}$ Therapeutic drug monitoring involves direct measurement of serum antibiotic concentrations and timely comparison with a therapeutic target to facilitate adjustments by the clinician or any dosing software.

\section{Fluid}

\section{Type of fluid}

Choice of non-blood product can be broadly divided into crystalloids and colloids. Crystalloids include normal saline or balanced solutions (eg lactated Ringer's solution [B Braun, US], Hartmann's solution [Fresenius Kabi, Australia], Plasma-Lyte 148 [Baxter, US]). Colloids include natural human albumin and semi-synthetic solutions (gelatin-like Gelofusine [B Braun, US] or Haemaccel [Sanofi, France], dextran, and hydroxyethyl starch). Normal saline has a high chloride content and may produce hyperchloraemic acidosis and renal vasoconstriction. Balanced solutions minimise these side-effects by using lactate 
TABLE 3. Factors affecting antibiotic pharmacokinetics in critically ill patients

\begin{tabular}{|c|c|c|}
\hline Factor & Cause/definition & Implication \\
\hline Fluid overload & $\begin{array}{l}\text { Capillary leakage and fluid } \\
\text { extravasation from SIRS, compounded } \\
\text { by fluid resuscitation }\end{array}$ & $\begin{array}{l}\text { Increases volume of distribution for hydrophilic antibiotics (eg } \beta \text {-lactams, } \\
\text { aminoglycosides, vancomycin, and linezolid). Reduces the time to reach } \\
\text { effective therapeutic concentration }\end{array}$ \\
\hline Hypoalbuminaemia & Serum albumin $<25 \mathrm{~g} / \mathrm{L}$ & $\begin{array}{l}\text { Raises unbound fraction of protein-bound antibiotics (eg ceftriaxone, } \\
\text { flucloxacillin, ertapenem, and daptomycin) resulting in: } \\
\text { 1. raised antibiotic activity (unbound fraction) in the early dosing interval } \\
\text { 2. increased volume of distribution reduces peak concentration } \\
\text { 3. increased elimination in the later dosing interval }\end{array}$ \\
\hline Microvascular failure & Sepsis and use of vasopressors & $\begin{array}{l}\text { Impairs tissue penetration of antibiotics. Serum concentration becomes an } \\
\text { imprecise guide }\end{array}$ \\
\hline $\begin{array}{l}\text { Augmented renal } \\
\text { clearance }\end{array}$ & $\begin{array}{l}\text { Vasodilation, increased cardiac output, } \\
\text { and enhanced renal perfusion }\end{array}$ & $\begin{array}{l}\text { Increases elimination of antibiotics predominantly excreted by the kidneys (eg } \\
\beta \text {-lactams, aminoglycosides, vancomycin) }\end{array}$ \\
\hline Acute kidney injury & Multi-organ dysfunction syndrome & $\begin{array}{l}\text { Impairs elimination of antibiotics predominantly excreted by the kidneys (eg } \\
\beta \text {-lactams, aminoglycosides, vancomycin). The effect of RRT on antibiotic } \\
\text { dosing is dependent on the mode and dose of RRT, and the sieving or } \\
\text { saturation coefficient of the antibiotic }\end{array}$ \\
\hline Hepatic dysfunction & Multi-organ dysfunction syndrome & $\begin{array}{l}\text { Impairs elimination of antibiotics predominantly cleared/metabolised by the liver } \\
\text { (eg tigecycline) }\end{array}$ \\
\hline
\end{tabular}

Abbreviations: RRT = renal replacement therapy; SIRS = systemic inflammatory response syndrome

or acetate as buffers. Weak evidence suggests that balanced solutions compared with normal saline reduce acute kidney injury (AKI), the need for renal replacement therapy (RRT), and mortality in sepsis. ${ }^{25,26}$ Nonetheless, the recent SPLIT trial did not find a difference in AKI among a heterogeneous group of ICU patients who received a balanced crystalloid or saline, although the study recruited predominantly postoperative patients at low risk who received small doses (median, $2 \mathrm{~L}$ ) of fluid. ${ }^{27}$

Colloids theoretically maintain a higher oncotic pressure and hence intravascular volume but the CRISTAL (Colloids Versus Crystalloids for the Resuscitation of the Critically Ill) trial found no mortality difference among ICU patients with hypovolaemic shock who were resuscitated with either colloids or crystalloids. ${ }^{28}$ Dextran has ceased to be a resuscitation fluid due to its high anaphylactoid potential, impact on platelet aggregation with resultant bleeding complications, and interference with erythrocyte cross-matching. Gelatins have the highest risk among the colloids for anaphylactoid reaction and the lowest intravascular persistence due to their rapid urinary excretion. Hydroxyethyl starch is not advisable for acute volume resuscitation because it deposits in the kidneys, liver, skin and other tissues, and is associated with increased mortality, AKI, new-onset hepatic failure, and higher incidences of pruritus and rash. ${ }^{29-32}$ Concerning albumin, the SAFE (Saline versus Albumin Fluid Evaluation) trial $^{33}$ demonstrated no survival benefit among a general ICU population when either $4 \%$ albumin or normal saline was used for fluid resuscitation, but predefined subgroup analysis suggested a trend towards improved survival in patients with severe sepsis who received albumin solution. A decade later, however, the ALBIOS (Albumin Italian Outcome Sepsis) study of patients with severe sepsis could not confirm a survival benefit when albumin was used in addition to crystalloids compared with crystalloids alone to maintain a serum albumin level of $\geq 30 \mathrm{~g} / \mathrm{L}$, although there was a small haemodynamic advantage and post-hoc subgroup analysis showed a significantly lower 90 -day mortality in patients with septic shock who received albumin. ${ }^{34}$

In summary, crystalloids (possibly balanced solutions) remain the initial fluid of choice in the resuscitation of sepsis. Routine use of albumin is not warranted given its higher cost, but it may be considered in patients with septic shock who do not respond to crystalloid. There is no evidence that gelatins are more beneficial, and dextran and hydroxyethyl starch should be avoided.

\section{Assessment of fluid responsiveness}

Both under- and over-hydration can be harmful. ${ }^{35}$ It is therefore recommended that $30 \mathrm{~mL} / \mathrm{kg}$ crystalloid be given with reassessment of fluid responsiveness (defined as $>10 \%-15 \%$ increase in stroke volume in response to volume administration) or tissue perfusion afterwards. Static indices like CVP and pulmonary capillary wedge pressure are not good indicators of fluid responsiveness, and are not recommended for use to guide fluid therapy. Dynamic indices obtained by inducing a change in the preload and monitoring the corresponding change in cardiac output (CO) or its derivatives should be used instead (Table 4).

An arterial waveform pulse pressure variation (PPV) of $>13 \%$, induced by heart-lung interactions 
TABLE 4. Assessment of fluid responsiveness

\begin{tabular}{|c|c|c|c|}
\hline Technique & Setting & Device & $\begin{array}{l}\text { Threshold values for fluid } \\
\text { responsiveness }\end{array}$ \\
\hline PPV & $\begin{array}{l}\text { Mechanically ventilated with tidal } \\
\text { volume } \geq 8 \mathrm{~mL} / \mathrm{kg} \text {, in the absence of } \\
\text { spontaneous breathing activity and } \\
\text { arrhythmias }\end{array}$ & $\begin{array}{l}\text { Arterial blood pressure transducer } \\
\text { and patient monitor }\end{array}$ & $\begin{array}{l}100 \times(\text { Ppmax }- \text { Ppmin }) /[(P p m a x+ \\
\text { Ppmin)/2] } \geq 13 \%\end{array}$ \\
\hline Passive leg raising & $\begin{array}{l}\text { Validated in the presence of } \\
\text { spontaneous breathing and arrhythmias }\end{array}$ & $\begin{array}{l}\text { Device to measure cardiac } \\
\text { output or surrogate (transthoracic } \\
\text { echocardiography, oesophageal/ } \\
\text { transthoracic Doppler, calibrated } \\
\text { pulse contour analysis, bioreactance, } \\
\text { pulmonary artery catheter, arterial } \\
\text { blood pressure transducer) }\end{array}$ & $\begin{array}{l}\text { Depending on index used } \\
\text { Aortic or subaortic VTI increases } \geq 15 \% \text {; } \\
\text { accuracy drops if assessed by changes } \\
\text { in pulse pressure instead of cardiac } \\
\text { output or surrogate }\end{array}$ \\
\hline Mini-fluid challenge & $\begin{array}{l}\text { Mechanically ventilated at low-tidal- } \\
\text { volume (<8 mL/kg ideal body weight) } \\
\text { patients without spontaneous breathing } \\
\text { or arrhythmias challenged with } 100 \mathrm{~mL} \\
4 \% \text { human albumin over } 1 \mathrm{~min}\end{array}$ & $\begin{array}{l}\text { Arterial blood pressure transducer } \\
\text { and patient monitor }\end{array}$ & $\Delta \mathrm{PPV}_{100} \geq 2 \%$ \\
\hline \multirow[t]{2}{*}{$\begin{array}{l}\text { Respiratory variation } \\
\text { of inferior vena cava }\end{array}$} & $\begin{array}{l}\text { Mechanically ventilated with tidal } \\
\text { volume } \geq 8 \mathrm{~mL} / \mathrm{kg}\end{array}$ & Echocardiography & $\begin{array}{l}100 \times(\mathrm{Dmax}-\mathrm{Dmin}) / \mathrm{Dmin} \geq 18 \% \\
100 \times(\mathrm{Dmax}-\mathrm{Dmin}) /[(\mathrm{Dmax}+\mathrm{Dmin}) / 2] \\
\geq 12 \%\end{array}$ \\
\hline & Spontaneously breathing & Echocardiography & $\begin{array}{l}100 \times(\mathrm{Dmax}-\mathrm{Dmin}) / \mathrm{Dmax} \geq 40 \% \\
\mathrm{AUC} \text { of } \mathrm{ROC}=0.77 \text { only: a value } \geq 40 \% \\
\text { more likely to be fluid responsive, } \\
\text { but }<40 \% \text { cannot exclude fluid } \\
\text { responsiveness }\end{array}$ \\
\hline
\end{tabular}

Abbreviations: AUC = area under curve; Dmax / Dmin = maximum / minimum IVC diameter; IVC = inferior vena cava; Ppmax / Ppmin = maximal / minimal pulse pressure; $\mathrm{PPV}=$ pulse pressure variation; $\Delta \mathrm{PPV}{ }_{100}=$ reduction in pulse pressure variation after $100-\mathrm{mL}$ mini-fluid challenge; $\mathrm{ROC}=$ receiver operating characteristic curve; $\mathrm{VTI}$ = subaortic velocity time index

during mechanical ventilation, predicts fluid responsiveness with a high degree of accuracy in controlled settings. ${ }^{36,37}$ Its accuracy, however, is lowered by arrhythmia, spontaneous breathing activity, low-tidal-volume ventilation $(<8 \mathrm{~mL} / \mathrm{kg}$ ideal body weight), low heart-rate-to-respiratoryrate ratio $(<3.6)$, and right ventricular dysfunction (peak systolic velocity of tricuspid annulus $<0.15$ $\mathrm{m} / \mathrm{s}$ ). Raised intra-abdominal pressure (IAP) exaggerates PPV, and one study found that PPV/ IAP of $<1.41$ could identify false-positive patients. ${ }^{38}$ These confounders limit the application of PPV in routine clinical practice, in particular during protective ventilation for acute respiratory distress syndrome (ARDS).

A virtual fluid challenge test with passive leg raising can avoid the above caveats as it does not rely on mechanical ventilation to induce changes in preload and, unlike other methods, has been validated in patients with breathing efforts and arrhythmia. When coupled with CO monitoring, passive leg raising has an excellent predictive accuracy. ${ }^{39}$ Accuracy drops when arterial pulse pressure instead of $\mathrm{CO}$ is used, as well as in patients with raised IAP of $\geq 16 \mathrm{~mm} \mathrm{Hg.}{ }^{40}$

A mini-fluid challenge $(100 \mathrm{~mL}$ infused rapidly over 1 minute) is an alternative method and limits cumulative positive fluid balance in non-responders.
Unlike PPV, it remains accurate at times of lowtidal-volume ventilation. ${ }^{41}$

Respiratory variation of the inferior vena cava diameter is another accurate marker of fluid responsiveness in patients who are mechanically ventilated, ${ }^{42}$ but its use in spontaneously breathing patients is more controversial.

\section{Vasopressors}

Guidelines of SSC recommend maintaining MAP at a minimal of $65 \mathrm{~mm} \mathrm{Hg} .{ }^{14}$ The SEPSISPAM (Sepsis and Mean Arterial Pressure) Investigators studied 776 septic shock patients, and found that targeting a MAP of $80-85 \mathrm{~mm} \mathrm{Hg}$ rather than $65-70 \mathrm{~mm} \mathrm{Hg}$ did not result in any difference in 28- or 90-day mortality. ${ }^{43}$ A vasopressor should be considered when MAP of $\geq 65 \mathrm{~mm} \mathrm{Hg}$ cannot be maintained despite adequate fluid resuscitation.

For the choice of vasopressors, studies that compared norepinephrine (with or without additional dobutamine in patients with low CO) with epinephrine found no difference in all-cause 28-day mortality, ${ }^{44}$ or the time to achievement of a clinician-prescribed MAP goal. ${ }^{45}$ Epinephrine use was associated with significant tachycardia and lactic acidosis that did not affect haemodynamic stabilisation or survival. The hyperlactataemia represents exaggerated aerobic glycolysis instead 
of ongoing tissue hypoxia, but potentially interferes with interpretation of serial serum lactate measurements. The 2008 VASST (Vasopressin and Septic Shock Trial) ${ }^{46}$ randomised 779 septic shock patients to receive either norepinephrine alone or norepinephrine plus low-dose vasopressin (0.03 $\mathrm{U} / \mathrm{min}$ ), and found no difference in all-cause 28-day mortality. The SOAP II Trial randomised 1679 patients with shock to receive either norepinephrine or dopamine, and found no difference in all-cause 28-day mortality but a significantly higher rate of arrhythmias in the dopamine group (the number needed to harm was 9). In their subgroup analysis, dopamine was associated with higher mortality in cardiogenic shock, but not septic and hypovolaemic shock. ${ }^{47}$

Norepinephrine is therefore recommended as the first-line vasopressor for septic shock. In refractory hypotension, epinephrine or lowdose vasopressin (0.03 units/min) may be added Dopamine should be avoided except in highly selected patients who are bradycardic and at low risk of tachyarrhythmias.

\section{Resuscitation endpoints}

The optimal goal for sepsis resuscitation remains unknown. While under resuscitation is detrimental, achieving supranormal targets has also been shown to cause harm. ${ }^{48}$ The MAP (perfusion pressure) of $\geq 65 \mathrm{~mm} \mathrm{Hg}$ and urine output of $\geq 0.5 \mathrm{~mL} / \mathrm{kg} / \mathrm{h}$ are the recommended targets. The EMShockNet Trial showed that there was no difference in hospital mortality when using lactate clearance $(>10 \%)$ or $\mathrm{ScvO}_{2}(>70 \%)$ as goals of early sepsis resuscitation. ${ }^{49}$ Hyperlactataemia in sepsis, however, can result from increased production driven by endogenous or exogenous epinephrine-stimulated aerobic glycolysis, endotoxin inhibition of pyruvate dehydrogenase, and decreased lactate metabolism due to liver and renal dysfunction. Thus, persistent hyperlactataemia does not necessarily indicate anaerobic metabolism and tissue hypoxia, and should not be solely relied on to guide therapy that aims to boost oxygen delivery in patients who are otherwise clinically improving. Conversely, normalisation of serum lactate is reassuring as it is associated with reduced hospital mortality in critically ill patients..$^{50}$

\section{Adjunctive therapy}

\section{Blood transfusion}

In the original EGDT protocols, once $\mathrm{ScvO}_{2}$ drops below $70 \%$, blood transfusion to achieve a haematocrit level of $\geq 30 \%$ was recommended to boost oxygen delivery. The 1999 TRICC (Transfusion Requirements in Critical Care) trial demonstrated lower rates of in-hospital mortality with a restrictive rather than liberal transfusion strategy. This trial, however, excluded septic shock patients. The 2014 TRISS (Transfusion Requirements in Septic Shock) trial randomised 998 septic shock patients to either a liberal blood transfusion strategy with a transfusion threshold of haemoglobin of $\leq 90 \mathrm{~g} / \mathrm{L}$ or a restrictive strategy with a threshold of $\leq 70 \mathrm{~g} / \mathrm{L} .{ }^{51}$ Mortality at 90 days, rate of ischaemic events, and use of life support were similar. A transfusion threshold of $70 \mathrm{~g} / \mathrm{L}$ is therefore recommended. For patients with ongoing acute coronary syndrome or chronic cardiovascular disease, targeting a higher haemoglobin level of $100 \mathrm{~g} / \mathrm{L}$ might be beneficial but remains to be proven. ${ }^{52}$

\section{Glucocorticoids}

Glucocorticoids have anti-inflammatory and immunosuppressive effects. Despite the positive Annane Trial in 2002, the subsequently larger multicentre CORTICUS (Corticosteroid Therapy of Septic Shock) Trial ${ }^{53}$ was negative. It randomised 499 patients with septic shock to receive 6-hourly 50-mg hydrocortisone or placebo, with the dose tapered over 11 days. Hydrocortisone did not improve 28-day survival in patients with septic shock, and should not be routinely used for septic shock before adequate fluid resuscitation and vasopressor therapy. ${ }^{14}$ If used in refractory shock, early administration within 9 hours of commencement of vasopressor is advised. ${ }^{54}$

\section{Glucose control}

Tight glycaemic control (blood glucose, 4.4-6.1 mmol/L) was once commonly practised after the 2001 Leuven Surgical Trial. In 2009, the NICE-SUGAR (Normoglycemia in Intensive Care EvaluationSurviving Using Glucose Algorithm Regulation) study randomised 6104 ICU patients, and showed that intensive glucose control (4.5-6.0 $\mathrm{mmol} / \mathrm{L})$ increased mortality compared with a target of $<10$ $\mathrm{mmol} / \mathrm{L} .{ }^{55}$ Post-hoc analysis further demonstrated an association between hypoglycaemia and an increased risk of death in a dose-response relationship. This association was strongest for death from distributive, including septic shock. ${ }^{56}$ Guidelines of SSC recommend targeting an upper blood glucose level of $<10 \mathrm{mmol} / \mathrm{L}$ to reduce the risk of hypoglycaemia. ${ }^{14}$

\section{Organ support}

\section{Kidney}

The optimal timing of RRT in the absence of overt life-threatening complications (severe metabolic acidosis, hyperkalaemia, and/or fluid overload) is uncertain. Prior studies as well as the recent ELAIN (Early vs Late Initiation of Renal Replacement Therapy in Critically Ill Patients With Acute Kidney Injury ${ }^{57}$ ) and AKIKI (Artificial Kidney Initiation in Kidney Injury ${ }^{58}$ ) trials have yielded contradictory results, partly because of the heterogeneous 
definitions of 'early' and 'late' initiation of RRT. It is hoped that the upcoming IDEAL-ICU (Initiation of Dialysis Early versus Delayed in Intensive Care Unit $^{59}$ ) and STARRT-AKI (Standard versus accelerated initiation of renal replacement therapy in acute kidney injury ${ }^{60}$ ) trials will provide more evidence on the subject. Regarding the intensity of renal support in critically ill patients with AKI, an effluent rate of $25 \mathrm{~mL} / \mathrm{kg} / \mathrm{h}$ is considered adequate and high-volume haemofiltration is not superior. ${ }^{61,62}$ Survival benefit of blood purification strategies has yet to be proven.

\section{Lungs}

Of note, ARDS is a frequent complication of sepsis. Optimal ventilatory support prevents further lung injury and the resultant biotrauma from cytokine release. A lung protective strategy with low tidal volume $(6 \mathrm{~mL} / \mathrm{kg}$ ideal body weight) remains the cornerstone of treatment. ${ }^{63} \mathrm{~A}$ higher positive endexpiratory pressure should be reserved for patients with moderate-to-severe ARDS as defined by the latest Berlin definition. ${ }^{64}$ Early (intubated for $<36$ hours) and sustained ( $\geq 16$ consecutive hours per day) prone positioning in moderate-to-severe ARDS has proven survival advantage when practised in conjunction with lung protective ventilation. ${ }^{65}$

\section{Conclusion}

Optimal sepsis management involves both refinement of clinical interventions and administrative logistics for the timeliness of their delivery. Early recognition of sepsis, timely source control, prompt and effective antibiotic administration at the right dose, immediate fluid resuscitation as guided by bedside reassessment, and dynamic indices of fluid responsiveness remain the mainstay of sepsis management.

\section{Declaration}

All authors have disclosed no conflicts of interest.

\section{References}

1. Gaieski DF, Edwards JM, Kallan MJ, Carr BG. Benchmarking the incidence and mortality of severe sepsis in the United States. Crit Care Med 2013;41:1167-74.

2. Kaukonen KM, Bailey M, Pilcher D, Cooper DJ, Bellomo R. Systemic inflammatory response syndrome criteria in defining severe sepsis. N Engl J Med 2015;372:1629-38.

3. Bone RC, Balk RA, Cerra FB, et al. Definitions for sepsis and organ failure and guidelines for the use of innovative therapies in sepsis. The ACCP/SCCM Consensus Conference Committee. American College of Chest Physicians/Society of Critical Care Medicine. Chest 1992;101:1644-55.

4. Singer M, Deutschman CS, Seymour CW, et al. The Third International Consensus Definitions for Sepsis and Septic Shock (Sepsis-3). JAMA 2016;315:801-10.

5. Wacker C, Prkno A, Brunkhorst FM, Schlattmann P.
Procalcitonin as a diagnostic marker for sepsis: a systematic review and meta-analysis. Lancet Infect Dis 2013;13:42635.

6. Rivers E, Nguyen B, Havstad S, et al. Early goal-directed therapy in the treatment of severe sepsis and septic shock. N Engl J Med 2001;345:1368-77.

7. Dellinger RP, Levy MM, Rhodes A, et al. Surviving sepsis campaign: international guidelines for management of severe sepsis and septic shock: 2012. Crit Care Med 2013;41:580-637.

8. ProCESS Investigators, Yealy DM, Kellum JA, et al. A randomized trial of protocol-based care for early septic shock. N Engl J Med 2014;370:1683-93.

9. ARISE Investigators; ANZICS Clinical Trial Group, Peake SL, Delany A, et al. Goal-directed resuscitation for patients with early septic shock. N Engl J Med 2014;371:1496-506.

10. Mouncey PA, Osborn TM, Power GS, et al. Trial of early, goal-directed resuscitation for septic shock. N Engl J Med 2015;372:1301-11.

11. Surviving Sepsis Campaign. Updated bundles in response to new evidence. Available from: http://www.survivingsepsis. org/SiteCollectionDocuments/SSC_Bundle.pdf. Accessed 5 Jun 2016.

12. Waibel BH, Rotondo MF. Damage control for intraabdominal sepsis. Surg Clin North Am 2012;92:243-57.

13. Ferrer R, Martin-Loeches I, Phillips G, et al. Empirical antibiotic treatment reduces mortality in severe sepsis and septic shock from the first hour: results from a guidelinebased performance improvement program. Crit Care Med 2014;42:1749-55.

14. Rhodes A, Evans LE, Alhazzani W, et al. Surviving Sepsis Campaign: International Guidelines for Management of Sepsis and Septic Shock: 2016. Crit Care Med 2017;45:486552.

15. Kumar A, Roberts D, Wood KE, et al. Duration of hypotension before initiation of effective antimicrobial therapy is the critical determinant of survival in human septic shock. Crit Care Med 2006;34:1589-96.

16. Sterling SA, Miller WR, Pryor J, Puskarich MA, Jones AE. The impact of timing of antibiotics on outcomes in severe sepsis and septic shock: a systematic review and metaanalysis. Crit Care Med 2015;43:1907-15.

17. Almeida M, Ribeiro O, Aragão I, et al. Differences in compliance with Surviving Sepsis Campaign recommendations according to hospital entrance time: day versus night. Crit Care 2013;17:R79.

18. Vincent JL, Rello J, Marshall J, et al. International study of the prevalence and outcomes of infection in intensive care units. JAMA 2009;302:2323-9.

19. Kumar A, Safdar N, Kethireddy S, Chateau D. A survival benefit of combination antibiotic therapy for serious infections associated with sepsis and septic shock is contingent only on the risk of death: a meta-analytic/metaregression study. Crit Care Med 2010;38:1651-64.

20. Paul M, Benuri-Silbiger I, Soares-Weiser K, Leibovici L. Beta lactam monotherapy versus beta lactamaminoglycoside combination therapy for sepsis in immunocompetent patients: systematic review and metaanalysis of randomised trials. BMJ 2004;328:668.

21. de Jong E, van Oers JA, Beishuizen A, et al. Efficacy and safety of procalcitonin guidance in reducing the duration of antibiotic treatment in critically ill patients: a randomised, controlled, open-label trial. Lancet Infect Dis 2016;16:819- 
27.

22. Jamal JA, Economou CJ, Lipman J, Roberts JA. Improving antibiotic dosing in special situations in the ICU: burns, renal replacement therapy and extracorporeal membrane oxygenation. Curr Opin Crit Care 2012;18:460-71.

23. Choi G, Gomersall CD, Tian Q, Joynt GM, Li AM, Lipman J. Principles of antibacterial dosing in continuous renal replacement therapy. Blood Purif 2010;30:195-212.

24. Roberts JA, Abdul-Aziz MH, Lipman J, et al. Individualised antibiotic dosing for patients who are critically ill: challenges and potential solutions. Lancet Infect Dis 2014;14:498-509.

25. Yunos NM, Bellomo R, Hegarty C, Story D, Ho L, Bailey M. Association between a chloride-liberal vs chloriderestrictive intravenous fluid administration strategy and kidney injury in critically ill adults. JAMA 2012;308:156672.

26. Rochwerg B, Alhazzani W, Sindi A, et al. Fluid resuscitation in sepsis: a systematic review and network meta-analysis. Ann Intern Med 2014;161:347-55.

27. Young P, Bailey M, Beasley R, et al. Effect of a buffered crystalloid solution vs saline on acute kidney injury among patients in the intensive care unit: The SPLIT Randomized Clinical Trial. JAMA 2015;314:1701-10.

28. Annane D, Siami S, Jaber S, et al. Effects of fluid resuscitation with colloids vs crystalloids on mortality in critically ill patients presenting with hypovolemic shock: the CRISTAL randomized trial. JAMA 2013;310:1809-17.

29. Brunkhorst FM, Engel C, Bloos F, et al. Intensive insulin therapy and pentastarch resuscitation in severe sepsis. $\mathrm{N}$ Engl J Med 2008;358:125-39.

30. Perner A, Haase N, Guttormsen AB, et al. Hydroxyethyl starch 130/0.42 versus Ringer's acetate in severe sepsis. N Engl J Med 2012;367:124-34.

31. Myburgh JA, Finfer S, Bellomo R, et al. Hydroxyethyl starch or saline for fluid resuscitation in intensive care. $\mathrm{N}$ Engl J Med 2012;367:1901-11.

32. Guidet B, Martinet O, Boulain T, et al. Assessment of hemodynamic efficacy and safety of $6 \%$ hydroxyethylstarch $130 / 0.4$ vs. $0.9 \% \mathrm{NaCl}$ fluid replacement in patients with severe sepsis: the CRYSTMAS study. Crit Care 2012;16:R94.

33. Finfer S, Bellomo R, Boyce N, et al. A comparison of albumin and saline for fluid resuscitation in the intensive care unit. N Engl J Med 2004;350:2247-56.

34. Caironi P, Tognoni G, Masson S, et al. Albumin replacement in patients with severe sepsis or septic shock. N Engl J Med 2014;370:1412-21.

35. Boyd JH, Forbes J, Nakada TA, Walley KR, Russell JA. Fluid resuscitation in septic shock: a positive fluid balance and elevated central venous pressure are associated with increased mortality. Crit Care Med 2011;39:259-65.

36. Marik PE, Cavallazzi R, Vasu T, Hirani A. Dynamic changes in arterial waveform derived variables and fluid responsiveness in mechanically ventilated patients: a systematic review of the literature. Crit Care Med 2009;37:2642-7.

37. Michard F, Boussat S, Chemla D, et al. Relation between respiratory changes in arterial pulse pressure and fluid responsiveness in septic patients with acute circulatory failure. Am J Respir Crit Care Med 2000;162:134-8.

38. Royer P, Bendjelid K, Valentino R, Résière D, Chabartier $\mathrm{C}$, Mehdaoui $\mathrm{H}$. Influence of intra-abdominal pressure on the specificity of pulse pressure variations to predict fluid responsiveness. J Trauma Acute Care Surg 2015;78:994-9.

39. Monnet X, Marik P, Teboul JL. Passive leg raising for predicting fluid responsiveness: a systematic review and meta-analysis. Intensive Care Med 2016;42:1935-47.

40. Mahjoub Y, Touzeau J, Airapetian N, et al. The passive leg-raising maneuver cannot accurately predict fluid responsiveness in patients with intra-abdominal hypertension. Crit Care Med 2010;38:1824-9.

41. Mallat J, Meddour M, Durville E, et al. Decrease in pulse pressure and stroke volume variations after mini-fluid challenge accurately predicts fluid responsiveness. Br J Anaesth 2015;115:449-56.

42. Barbier C, Loubières $Y$, Schmit C, et al. Respiratory changes in inferior vena cava diameter are helpful in predicting fluid responsiveness in ventilated septic patients. Intensive Care Med 2004;30:1740-6.

43. Asfar P, Meziani F, Hamel JF, et al. High versus low bloodpressure target in patients with septic shock. N Engl J Med 2014;370:1583-93.

44. Annane D, Vignon P, Renault A, et al. Norepinephrine plus dobutamine versus epinephrine alone for management of septic shock: A randomised trial. Lancet 2007;370:676-84.

45. Myburgh JA, Higgins A, Jovanovska A, et al. A comparison of epinephrine and norepinephrine in critically ill patients. Intensive Care Med 2008;34:2226-34.

46. Russell JA, Walley KR, Singer J, et al. Vasopressin versus norepinephrine infusion in patients with septic shock. N Engl J Med 2008;358:877-87.

47. De Backer D, Biston P, Devriendt J, et al. Comparison of dopamine and norepinephrine in the treatment of shock. N Engl J Med 2010;362:779-89.

48. Hayes MA, Timmins AC, Yau EH, Palazzo M, Hinds CJ, Watson D. Elevation of systemic oxygen delivery in the treatment of critically ill patients. N Engl J Med 1994;330:1717-22.

49. Jones AE, Shapiro NI, Trzeciak S, et al. Lactate clearance vs central venous oxygen saturation as goals of early sepsis therapy: a randomized clinical trial. JAMA 2010;303:73946.

50. Nichol A, Bailey M, Egi M, et al. Dynamic lactate indices as predictors of outcome in critically ill patients. Crit Care 2011;15:R242.

51. Holst LB, Haase N, Wetterslev J, et al. Lower versus higher hemoglobin threshold for transfusion in septic shock. N Engl J Med 2014;371:1381-91.

52. Docherty AB, O'Donnell R, Brunskill S, et al. Effect of restrictive versus liberal transfusion strategies on outcomes in patients with cardiovascular disease in a non-cardiac surgery setting: systematic review and meta-analysis. BMJ 2016;352:i1351.

53. Sprung CL, Annane D, Keh D, et al. Hydrocortisone therapy for patients with septic shock. N Engl J Med 2008;358:11124.

54. Katsenos CS, Antonopoulou AN, Apostolidou EN, et al. Early administration of hydrocortisone replacement after the advent of septic shock: impact on survival and immune response. Crit Care Med 2014;42:1651-7.

55. NICE-SUGAR Study Investigators, Finfer S, Chittock DR, et al. Intensive versus conventional glucose control in critically ill patients. N Engl J Med 2009;360:1283-97.

56. NICE-SUGAR Study Investigators, Finfer S, Liu B, et al. Hypoglycemia and risk of death in critically ill patients. $\mathrm{N}$ 
Engl J Med 2012;367:1108-18.

57. Zarbock A, Kellum JA, Schmidt C, et al. Effect of early vs delayed initiation of renal replacement therapy on mortality in critically ill patients with acute kidney injury: the ELAIN randomized clinical trial. JAMA 2016;315:2190-9.

58. Gaudry S, Hajage D, Schortgen F, et al. Initiation strategies for renal-replacement therapy in the Intensive Care Unit. N Engl J Med 2016;375:122-33.

59. Barbar SD, Binquet $C$, Monchi $M$, Bruyère R, Quenot JP. Impact on mortality of the timing of renal replacement therapy in patients with severe acute kidney injury in septic shock: the IDEAL-ICU study (initiation of dialysis early versus delayed in the intensive care unit): study protocol for a randomized controlled trial. Trials 2014;15:270.

60. Wald R, Adhikari NK, Smith OM, et al. Comparison of standard and accelerated initiation of renal replacement therapy in acute kidney injury. Kidney Int 2015;88:897-904.

61. RENAL Replacement Therapy Study Investigators, Bellomo R, Cass A, et al. Intensity of continuous renal- replacement therapy in critically ill patients. N Engl J Med 2009;361:1627-38.

62. Joannes-Boyau O, Honoré PM, Perez P, et al. High-volume versus standard-volume haemofiltration for septic shock patients with acute kidney injury (IVOIRE study): a multicentre randomized controlled trial. Intensive Care Med 2013;39:1535-46.

63. Ventilation with lower tidal volumes as compared with traditional tidal volumes for acute lung injury and the acute respiratory distress syndrome. The Acute Respiratory Distress Syndrome Network. N Engl J Med 2000;342:13018.

64. Briel M, Meade M, Mercat A, et al. Higher vs lower positive end-expiratory pressure in patients with acute lung injury and acute respiratory distress syndrome: systematic review and meta-analysis. JAMA 2010;303:865-73.

65. Guérin C, Reignier J, Richard JC, et al. Prone positioning in severe acute respiratory distress syndrome. N Engl J Med 2013;368:2159-68. 